\title{
Using Prezi In Higher Education
}

\author{
Nora Strasser, Friend University, USA
}

\begin{abstract}
PowerPoint can be viewed as boring and commonplace (Craig \& Amernic, 2006). While it is a great tool, using a more dynamic presentation editor may better capture the attention of a class or any other group of people. Having an editor that is cloud-based allows for more flexibility and collaboration than is possible with PowerPoint (Settle, Abrams, \& Baker, 2011). Prezi is a cloudbased presentation editor that allows the user to create presentations that zoom. The goal is to make presentations more dynamic in nature and not as linear in structure.

Being able to access your presentation from the internet also allows for a much more flexible working environment. Presentations can be edited at any place and any time. A link is available that will allow others to view the presentation as well. Also, any changes made to a presentation will be reflected in what a viewer sees. Students can use Prezi to much more easily work collaboratively on projects.
\end{abstract}

Keywords: Presentation; Prezi; Online

\section{INTRODUCTION}

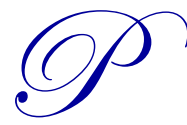

resentation software has centered around PowerPoint style editors for at least the last 20 years (Parks, 2012). While using PowerPoint in the classroom was considered to be cutting edge, it is now seen as the epitome of boring. Comments from students include statements such as "Not another boring PowerPoint presentation." Using PowerPoint typically fails to capture students' interest and/or to excite them. It no longer works as a tool to engage students in your lecture unless it involves more sophisticated elements such as movement (Clark, 2008).

Other options for presentations are available; one such option is Prezi. Prezi is an internet-based presentation software that allows you to store your presentations in the cloud. There are many advantages to using this software, including the fact that it is cloud-based and that it is more exciting than the standard presentation software. Prezi is very visually-oriented and always enhances a presentation that is well-designed. It is still important to design a presentation that is appropriate. Just as a PowerPoint presentation can be badly designed, so can a Prezi. It is important to focus on using Prezi in a way that enhances the information being presented rather than hinder it.

Prezi is based on the concept of being able to zoom in on items in the presentation (Settle, Abrams, \& Baker, 2011). Not only is this visually appealing, but it is practical as well. It tends to capture the audience's interest and presents information in a way that is less linear in structure. It can be used to emphasize the hierarchical nature of information and the connections within topics. Again, if you simply want a bulleted list, Prezi is probably not the best presentation utility for you. However, if you want to highlight the connections between topics and want a very visually oriented presentation, then Prezi is the correct choice. It can be used to emphasize the hierarchical nature of information and the connections within topics (Harris, 2011).

\section{DESCRIPTION}

Prezi is an online presentation program that offers storage of your presentation in the cloud. It is very different from PowerPoint in that its approach is non-linear. You are faced with a canvas instead of slides for creating your presentation. This means that you see the entire presentation at once instead of in discrete segments. 
This allows you to create a unity within your presentation, and the overall design of the canvas should emphasize the summary of your information. While this might seem overwhelming, the fact that Prezi allows you to zoom creates a movement that can emphasize important concepts and connections. The best guidelines for creating a Prezi emphasize that you need to create the overall design and then create parts that you can zoom in on to highlight certain information.

Several features allow you to customize Prezi for your specific material. While the entire presentation is displayed on a canvas, you can create a path that allows the presentation to proceed in a linear fashion. If you choose not to use a path, then you can choose to enter any segment of the presentation in any order. Both linear and non-linear presentation can be designed. Prezi also allows you the flexibility to alter this at any time, even during the actual presentation. Several templates are available that allow you to have ready-made paths and visuals.

Hierarchical relationships can be emphasized using the zoom feature which also allows you to hide certain aspects of the presentation until you want them shown. Questions can even be asked with the answers hidden within the presentation. The canvas can be zoomed in and/or out and it can also be rotated. Using a combination of these features will make a dynamic presentation that will maintain the interest of the students in a class. It is important to use these capabilities sparingly so that they do not become overwhelming for the viewer.

Another feature that is an exciting addition to the presentation software is the ability for students to collaborate. Since the presentations are stored online, the author of a presentation can give access to others not only to view the presentation, but to edit it as well. This means that students working in groups can create group presentations where each student has the ability to edit the presentation. Students can work collaboratively without being in the same room or even online at the same time.

One final feature that makes Prezi very valuable is that because it is stored online, any changes made will be instantly available for all to view. There is no problem with multiple copies and determining which changes were made in which version. A link to the presentation can also be given out and anyone with internet access can then view the presentation. It is also possible to make a presentation public so that anyone can view it without having the necessary link. If an error is discovered in the presentation, it can be changed even after the link has gone out and everyone viewing it from that point on will see the updated version.

Prezi is now also available on the iPad as a free app, so presentations can be accessed via iPad as well. This app is becoming more versatile with each update and now allows you to not only view a presentation, but create and edit a presentation as well. There is also a Prezi viewer for the iPhone.

\section{USES}

Prezi can be used to create complicated lecture support that easily shows the connections between topics. Instead of using discreet slides that break a topic up into disjointed parts, Prezi allows you to create a whole topic while being able to zoom in on specific parts. Topics are more fluid and dynamic as well as better represented by the structure. Prezi excels at demonstrating connections between topics.

While Prezi is a great tool to use during lectures, its most significant impact can be felt through its other uses. Students can use Prezi to create either individual or group presentations. Since educational licenses are free, students can easily use Prezi to develop more creative presentations. The collaborative nature of Prezi is a useful tool in the classroom setting. Students can work in groups and share editing of the Prezi. An author can create a Prezi and then invite others to edit as well. All changes that are made are instantly visible to everyone working on the Prezi, so there is no longer any concern about "what version" each person has.

Prezi can also be used to create what has been referred to as a "presume." This can take the place of a resume for students seeking a job. It can easily be used to highlight not only a student's accomplishments, but their skills as well. Prezi can also be used to create a portfolio. Since it is easy to include images and videos, Prezi can be used to create an artistic portfolio. Being able to work with visual objects - pictures, videos, web links, or animations - is a major feature of Prezi. 


\section{MISUSES}

One caution that is important to realize when using Prezi is that using it to essentially create a PowerPoint is not beneficial. Taking PowerPoint slides and converting them into a Prezi format does not accentuate the positive benefits of Prezi. It is then no better or worse than a PowerPoint presentation.

Instead, it is important to fully consider the features of Prezi and to utilize them to the fullest when designing a presentation. The concept that a topic needs to be viewed as a whole, with interconnected parts, underscores the design of an excellent Prezi. Creating slides that are not text-heavy is another important consideration.

Finally, it is important to use the zooming and turning features intentionally and sparingly as both can cause distress in the audience if not used properly. It is important to have a good reason for each use of these features. Using either too frequently, or for no reason other than show, is not a good way to create an excellent presentation.

\section{GOOD FEATURES}

A good Prezi emphasizes the following features: creativity, relationships, visualization, and collaboration.

\section{Creativity}

A Prezi can be a very creative outlet. Students should be encouraged to think outside the box when developing their Prezis. Creative thinking should be encouraged and facilitated; the best ones are those which demonstrate creativity in their design.

\section{Relationships}

A Prezi should demonstrate relationships between the parts and the whole topic of the presentation. Students need to be encouraged to think through these relationships and demonstrate them using the Prezi structure. Connections between topics are very important for creating a good presentation.

\section{Visualization}

A Prezi should be a very visual medium. Text-heavy presentations should be avoided in favor of the visual references that can be drawn from a topic. Using good visuals, such as pictures, videos, graphs, etc., is a good way to bring interest to a Prezi.

\section{Collaboration}

Prezis should be used to help students collaborate and improve group presentations. Collaboration is easy and not restricted to being in the same place at the same time.

\section{CONCLUSION}

Using Prezi in the higher education classroom can be a benefit to the educational experience. Lectures facilitated by Prezi can keep students' interest high and facilitate an understanding of the interconnectedness of topics. Prezi should not be used in all cases since some topics are better suited for presentations structured in a slide format. It is best to vary the delivery of lecture materials to decrease boredom and facilitate understanding. Students can benefit from the collaborative nature of the Prezi environment making their presentations more collaborative and creative. Prezi is one of many tools that can be used to keep the classroom an exciting and interactive place. 


\section{AUTHOR INFORMATION}

Nora Strasser is a Professor of Mathematics at Friends University in Wichita, KS. She has been teaching mathematics at the college level for over 25 years. She has a Bachelors and a Masters in Mathematics from the University of South Dakota. She also has a Doctorate in Higher Education from Nova Southeastern University. Nora is a recipient of the W.A. Young award for Excellence in Teaching. Her research interests include innovative ways to teach undergraduate mathematics particularly through the use of effective technology. E-mail: strasser@friends.edu

\section{REFERENCES}

1. Clark, J. (2008). PowerPoint and pedagogy: Maintaining student interest in university lectures. College Teaching, 56(1), 39-45.

2. Craig, R. J., \& Amernic, J. H. (2006). PowerPoint presentation technology and the dynamics of teaching. Innovative Higher Education, 31, 147-160.

3. Harris, D. (2011) Presentation software: Pedagogical constraints and potentials. Journal of Hospitality, Leisure, Sport and Tourism Education, 10(1), 72-84.

4. Parks, B. (2012), Death to PowerPoint. Bloomberg Businessweek. Retrieved June 20, 2013 from http://businessweek.com/

5. Settle, Q., Abrams, K. M., \& Baker, L. M. (2011) Using Prezi in the classroom. NACTA Journal, 55(4), 105-106. 